\title{
A STUDY RELATING TO DIVERSION OF AGRICULTRUAL CREDIT
}

\author{
AJIT SINGH \\ Associate Professor and Head, Department of Commerce and Management, Government Postgraduate College,
}

Ambala Cantonment, Haryana, India

\begin{abstract}
Agricultural development is an integral part of overall economic development of country like India. Though, the share of agricultural sector in gross domestic product (GDP) of India, has reduced from 58 percent (1951-52) to about 17.3 percent (2016-17), still it is considered a decisive driver, in order to achieve 8 to 9 percent growth in GDP. For agricultural development, adequate and timely availability of credit to the farmers is vital and indispensable, as it acts as a catalyst, to move the farmers from traditional to modern agriculture. Agricultural institutional credit has been growing continuously, after the nationalization and other banking sector reforms. But, past experience shows declining trend, in recovery performance of the banks and rural indebtedness, which is affecting adversely the disbursement of agricultural credit. The main reason behind the problem of low recovery is, misutilization of agricultural loan amount, as farmers do not utilize the loan amount, for the purpose for which it is taken. It becomes more dangerous, when agricultural credit amount is utilized for unproductive purposes, which do not generate any income. In light of the above, an attempt has been made in this paper, to analyze the different aspects relating to diversion of loans. The results indicate that, among purposes, 'Buying other inputs' and 'Consumption' are the main purposes, for the diversion of loan followed by 'Meeting social expenses'.

KEYWORDS: Agricultural Credit, Diversion \& Utilization of Loan
\end{abstract}

Received: Oct 01, 2017; Accepted: Oct 20, 2017; Published: Oct 31, 2017; Paper Id.: IJECRDEC20171

\section{INTRODUCTION}

Agriculture is the mainstay of the Indian economys, contributing about 15 percent of the GDP. In fact, agriculture is the way of life, a tradition, which for centuries has shaped the thought, the outlook, the culture and economic life of the people of India (National Agriculture policy, 2000). Though, the share of agricultural sector in gross domestic product (GDP) has reduced from 58 percent (1951-52) to about 17.3 percent (2016-17), still it is considered a decisive driver, in order to achieve 8 to 9 percent growth in GDP. Credit, no doubt, to any sector, is additional oxygen, to breath for better health of the economy but, its role in agriculture is crucial. Agricultural credit has played a great role, in increasing the agriculture production and also, to improve the standard of living of rural population. In fact, it is a unique source, as it provides the opportunity to use additional inputs and capital items, and to pay the cost from future earnings. Credit acts as a catalyst, to move the farmers from traditional to modern agriculture. It provides a command over resources and needed liquidity to farmers, who do not have sufficient funds to exploit opportunities (Sahu \& Rajshekhar, 2000). The farmers in the developing countries like India, cannot expect their capital needs to be fulfilled from savings because, their income from farm operations is barely sufficient, to provide the minimum necessities of life (Dhawan \& Kahlon, 1978). Now-a-days, adequate credit serves as an elevator and without adequate facilities, a farmer cannot attain their production targets. 
Thus, proper flow of credit is a must, for the development of agriculture in India.

It is alleged that, the agrarian system introduced by the survey settlement, was to be considered as an accentuating cause of indebtedness and more especially, to the restricted right of the cultivators, to transfer their holdings, which the survey settlement recognised. The predominant class of the Indian economy, continued to be the most neglected one, during the period proceeding independence and also, the initial years of independence. Evidence of such borrowings and indebtedness is abundant in periods, both before and after independence. This century- old plight of the Indian cultivators, particularly in terms of their perpetual and heavy debt burden, was first traced out very concretely and comprehensively, by the All India Rural Credit Survey of 1951-52. The survey (RBI, 1956) revealed that, in 1951-52, 69.2 percent of the cultivators were in debt, and average debt per cultivating family was Rs. 363.70. In 1961-62, the proportion of indebted cultivators was of the order of 66.7 percent and the average debt per cultivator household rose to Rs. 473.00 , as per the All India Rural Debt and Investment Survey. According to 1971-72 data, the proportion of indebted cultivating household was Rs. 605.00. All these give a pathetic picture, of how the cultivators in our country are deeply involved in debt.

Agricultural credit is provided on term basis and repayable in instalments. If a farmer is unable to repay in time, the bankers cannot recycle the recovered amount, for the other farmers. Past experience shows, a declining trend in recovery and performance of the banks, which is affecting the disbursement of agricultural credit, adversely. The recovery performance, depends upon the fact that, to what extent the farmers are successful to generate income with the use of the loan money. If, loans are properly utilized, the farmers can repay the loans in time. Thus, main reason behind the problem of low recovery is, misutilization of loan amount, as farmers do not utilize the loan amount for the purpose for which it is taken. It becomes more dangerous, when agricultural loan amount is utilized for unproductive purposes, which do not generate any income.

\section{OBJECTIVES OF THE STUDY}

The specific objectives of the present study are:

- To know the socio-economic pattern of farmers, diverting agricultural loans.

- To analyze the reasons for diversion of agricultural credit, by the farmers.

- To study the purpose-wise diversion of loans taken, by the farmers.

- To examine the expectations of farmers, to check the diversion.

\section{RESEARCH METHODOLOGY}

The present study is limited to Haryana State. To cover the wide range of farmers, spread all over the State, 'Multi-stage Stratified Random Sampling Technique' has been adopted. The State was stratified into four homogeneous agro-climate zones. Each zone, comprises 4 to 6 districts. Mewat, Panipat, Yamunanagar and Sirsa have been selected as sample districts, representing Zone I, Zone II, Zone III and Zone IV, respectively. The study is confined to 640 borrowing farmers, selecting 160 farmers from each district. In order to make the sample analytical more purposeful and representative of borrowing farmers in Haryana, they were grouped into four categories, as marginal farmers, small, medium and large farmers. Efforts were made, to choose samples from each of the above category. The primary data has been collected through questionnaires, filled by the loanee-farmers of Haryana State, which included both open ended and 
close ended questions. The respondents were personally interviewed, to collect the exact information. The collected primary data has been analyzed, by using various statistical techniques.

\section{RESULTS AND INTREPRETATION}

Proper utilization of agricultural credit is essential, as it creates its own source of repayment. Its diversion may lead to mounting uneconomic overdue and default, resulting into adverse effects on the repayment capacity of the farmer borrowers. The diversion may be, both for productive and unproductive purpose but, it is latter which is more dangerous. If the amount of loan is misutilized for unproductive purpose, farmer borrower will not be able to repay the loan.

Table I: Landholding-Wise Diversion of Loan by Farmers

\begin{tabular}{|l|c|c|c|c|c|}
\hline \multirow{2}{*}{ Zone } & \multicolumn{5}{|c|}{ Category of Farmers } \\
\cline { 2 - 6 } & Marginal & Small & Medium & Big & Total \\
\hline \multirow{2}{*}{ Zone I } & 8 & 16 & 19 & 7 & 50 \\
& $(16.0)$ & $(32.0)$ & $(38.0)$ & $(14.0)$ & $(100.0)$ \\
\hline \multirow{2}{*}{ Zone II } & 3 & 18 & 30 & 15 & 66 \\
& $(4.5)$ & $(27.3)$ & $(45.5)$ & $(22.7)$ & $(100.0)$ \\
\hline \multirow{2}{*}{ Zone III } & 0 & 4 & 0 & 7 & 11 \\
& $(0.0)$ & $(36.4)$ & $(0.0)$ & $(63.6)$ & $(100.0)$ \\
\hline \multirow{2}{*}{ Zone IV } & 0 & 1 & 6 & 21 & 28 \\
& $(0.0)$ & $(3.6)$ & $(21.4)$ & $(75.0)$ & $(100.0)$ \\
\hline \multirow{2}{*}{ Total } & 11 & 39 & 55 & 50 & 155 \\
& $(7.1)$ & $(25.2)$ & $(35.5)$ & $(32.2)$ & $(100.0)$ \\
\hline
\end{tabular}

Note: Figures in parentheses are percentages to total

Table I, indicates landholding-wise diversion of agricultural credit, by respondent farmers. It shows that, maximum of such borrowers are found in Zone II and Zone I and minimum in Zone III. In addition to this, the diversion pattern is also not uniform, in all the four zones.

\section{Reasons for Diversion of Loans}

There may be various reasons for diversion of agricultural loans. Table II, depicts some of the general reasons for diversion of loans. Efforts were made, to find out the views of respondents at five-point scale.

Table II: Reasons for Diversion of Loans by Farmers

\begin{tabular}{|c|l|c|c|c|}
\hline Sr. & \multicolumn{2}{|c|}{ Problems } & \multicolumn{3}{c|}{ Test Value = 3 } \\
\cline { 3 - 5 } No. & & Mean & Mean Difference & t-value \\
\hline 1 & Cannot get Loan for Actual Purpose & 3.98 & $0.981^{*}$ & 54.664 \\
\hline 2 & High rate of Interest on Loan for Actual Purpose & 3.91 & $0.911^{*}$ & 48.224 \\
\hline 3 & Because it was insufficient for Agricultural Purpose & 3.64 & $0.642^{*}$ & 26.128 \\
\hline 4 & Loan was received Late & 2.52 & $-0.480^{*}$ & -12.186 \\
\hline
\end{tabular}

* Significant at $1 \%$ level

Cannot get Loan for Actual Purpose, has been found the most important reason for diversion of loan, with mean value $=3.98(\mathrm{t}=54.664)$. It is hard, knowing the fact that, credit to farmers is provided for some specific purposes only. The next important reason for diversion is, 'High rate of Interest on Loan for Actual Purpose' $($ Mean $=3.91, t=48.224)$, followed by 'Because it was insufficient for Agricultural Purpose' (Mean = 3.64, $\mathrm{t}=26.128)$. The mean values of all these reasons are found to be on the higher side of hypothetical value and significant. 'Loan was received Late' $($ Mean $=2.52, \mathrm{t}=$ -12.186), is the least important reason, for the diversion of loan. 


\section{Purpose-Wise Utilization Pattern of Diverted Agricultural Loans}

Table III, indicates the purposes for which the diverted loans are utilized. To analyze the importance of these purposes, two-tailed t-test of mean values has been conducted. The Table shows that, 'Buying other Inputs' (Mean = 4.05, $\mathrm{t}$ $=68.667$ ) has been found, the most important purpose for which diverted loans are utilized.

Table III: Purpose-Wise Utilization Pattern of Diverted Loans

\begin{tabular}{|c|l|c|c|c|}
\hline \multirow{2}{*}{ Sr. No. } & \multicolumn{3}{|c|}{ Problems } & \multicolumn{3}{c|}{ Test Value = 3 } \\
\cline { 3 - 5 } & & Mean & Mean Difference & t-value \\
\hline 1 & Used for Buying other Inputs & 4.05 & $1.053^{*}$ & 68.667 \\
\hline 2 & Used for Consumption Purposes & 4.02 & $1.016^{*}$ & 64.359 \\
\hline 3 & Used for meeting Social Expenses & 4.03 & $1.027^{*}$ & 61.338 \\
\hline 4 & Used for repayment of other Loan & 3.33 & $0.325^{*}$ & 8.482 \\
\hline 5 & Reloaned the Amount & 1.86 & $-1.141^{*}$ & -32.840 \\
\hline
\end{tabular}

* Significant at $1 \%$ level

'Consumption Purpose' (Mean $=4.02, \mathrm{t}=64.359)$ is the second important purpose, for which diverted loans are utilized, followed by 'Meeting Social Expenses' (Mean $=4.03, \mathrm{t}=61.338$ ). The next important purpose is 'Repayment of other loan' (Mean $=3.33, \mathrm{t}=8.482$ ). The mean values of all these purposes are found to be on the higher side of the hypothetical value. The mean value of purpose 'Reloaned the amount' has been found, to be on the lower side of the hypothetical value. The mean values of all the above mentioned purposes are found significant, at 1 percent level of significance. Thus, it may be concluded that, agricultural loans are diverted, due to all the five purposes mentioned above.

Table IV, exhibits the correlation among the reasons and purposes, for the diversion of agricultural loans. For this purpose, Karl Pearson's Correlation Matrix has been used. Right upper triangle of the Table (in bold figures), exhibits the correlation and left lower triangle (unbold figures) presents the probability of Type I error. High, positive and significant correlation has been found between the variables, 'Used for buying other inputs' with 'Used for consumption purposes' (0.813) and with 'Used for meeting social expenses like marriage' (0.737). It may be due to the fact that, if loan is diverted and used for buying other inputs, it may also be used for consumption and meeting social expenses. Similarly, high positive correlation (0.797) has also been found between the variables ' Used of consumption purposes' and 'Used for meeting social expenses like marriage'.

High, positive and significant correlation (0.734) has been found between the variables 'Cannot get the loan for actual purposes' and 'High rate of interest on loan for actual purposes'. It is difficult for the farmers, to get loan for nonagricultural purposes and high rate of interest is charged by banks. Moderate positive correlation (0.511) has been found, between the variables 'High rate of interest on loan for actual purposes' and 'Because it was insufficient for agricultural purposes'.

Moderate and positive correlation (0.422) has been found, between the variables 'Cannot get the loan for actual purposes' and 'Because it was insufficient for agricultural purposes'. If any amount of agricultural loan is insufficient, that amount may be diverted for such purposes, for which farmers cannot get the loan. Similarly, moderate and positive correlation (0.359) has also been found between 'Used for meeting social expenses like marriage' and 'High rate of interest on loan for actual purpose'. If loan is availed for meeting social expenses, the farmers have to pay high rate of interest. The other values of correlation, shown with stars are also found significant at $1 \%$ and $5 \%$ level of significance, with low degree of correlation. 


\section{Expectations of Farmers}

Table V: Expectations from Banks Regarding Agricultural Credit

\begin{tabular}{|c|l|c|c|c|}
\hline Sr. No. & \multicolumn{1}{|c|}{ Agency } & Mean & Mode & Rank \\
\hline 1 & Provision of Quick Service & 2.64 & $1 *$ & 1 \\
\hline 2 & Simplified Procedure & 3.45 & $1 *$ & 2 \\
\hline 3 & Increase in Repayment Period & 2.72 & 2 & 3 \\
\hline 4 & Reduction in Interest Rates & 3.62 & 3 & 4 \\
\hline 5 & Supply of Loan as desired & 5.26 & 6 & 5 \\
\hline 6 & $\begin{array}{l}\text { Change in the periodicity of instalments in } \\
\text { case of long-term loans }\end{array}$ & 5.12 & $7 *$ & 6 \\
\hline 7 & $\begin{array}{l}\text { Exemption in recovery of loans in case of } \\
\text { Crop failure due to natural calamity }\end{array}$ & 5.19 & $7 *$ & 7 \\
\hline
\end{tabular}

*Being the same mode of Sr. No. $1 \& 2$ and $6 \& 7$, ranks have been given on the basis of Mean values of variables

Farmers, expect various facilities from the credit agencies, providing agricultural loans. To find out the expectations of the farmer respondents, about the facilities being provided by these agencies especially banks, the respondents were asked to give preferences to the facilities, generally being provided by banks.

Table V represents that, 'Provision of Quick Service' has been ranked as the first expectation by the farmers because, if loan is received late, it cannot be utilized properly and does not serve the intended purpose. 'Simplified Procedure' ranked as second expectation, as farmers are unable to avail loan, due to complicated procedure and formalities. 'Increase in Repayment Period' and 'Reduction in Interest Rates' are found the next important facilities, expected by farmers. The other expectations are found less important.

\section{CONCLUSIONS}

In the above analysis, regarding different aspects affecting diversion of loans, the results indicate that, among purposes, 'Buying other inputs' and 'Consumption' are the main purposes, for the diversion of loan followed by 'Meeting social expenses'. Due to long interval of time, between the sales of two crops, farmers do not have sufficient income to sustain during this period. Therefore, the consumption of loan should be advanced to the farmers, to avoid the diversion of loan advanced for agriculture and allied activities. 'Cannot get Loan for Actual Purpose', has been found as the most important reason, for diversion of loan. It is hard knowing fact that, credit to farmers is provided for some specific purposes only. The next important reason for diversion is 'High rate of Interest on Loan for Actual Purpose', followed by 'because it was insufficient for Agricultural Purpose'. The mean values of all these reasons are found to be on the higher side of hypothetical value and significant. 'Loan was received Late' is the least important reason, for diversion of loan. Farmers expect various facilities, from the credit agencies providing agricultural loans. 'Provision of Quick Service' has been ranked as the first expectation by the farmers because, if loan is received late, it cannot be utilized properly and does not serve the intended purpose. 'Simplified Procedure' is ranked as second expectation, as farmers are unable to avail loan, due to complicated procedure and formalities. 'Increase in Repayment Period' and 'Reduction in Interest Rates' are found the next important facilities, expected by farmers. The other expectations are found less important.

\section{REFERENCES}

1. Dhawan, K. C. and Kahlon, A. S. (1978). Adequacy and Productivity of credit on small farm in Punjab, Indian Journal of 
Agricultural Economics, 33 (4).

2. Dongre, Y. and D'Souja, P. (1988). Knowledge and attitude of rural borrowers based on emperial evidence. Financing Agriculture, $X X(1)$.

3. Goyal, S. K., Pandey, R. N. and Modi, M. K. (1993). Repayment capacity of defaulter and non-defaulter borrowers of cooperative societies in Haryana. Indian Cooperative Review, XXX (3).

4. Gupta, V. K. (1996). Problems of long term agricultural credit: a case of Baduan District (UP) (Unpublished doctoral thesis), Rohlikhand University, Barelly.

5. Hooda, A. S., Sharma, R. K. and Makija, V. K. (1995). Utilization of crop loan by farmers. Indian Economic Panorama, 5(3), Oct-Dec.

6. National Agriculture Policy (2000). Department of Agriculture and Cooperation, Government of India, New Delhi, p.1.

7. Rudra, R. C. and Mukherjee, S. (2003). Extent of use of credit in rural farm activities and the role of different sources of credit in Burdwan District in West Bengal. Environment and Ecology, 21(1), 165-173.

8. Reserve Bank of India (1956). All India Rural Credit Survey, the Survey Report, Bombay.

9. Sahu, G. B. and Rajshekhar, D. (2000). Gaps in the Agricultural Credit Cycle Flow: Some Lessons for Bankers, State Bank of India Monthly Review, 39(11), Novermber, p. 574.

\section{APPENDICES}

Table IV: Karl Pearson's Correlation Matrix Among Purposes and Reasons of Diversion of Loans

\begin{tabular}{|c|c|c|c|c|c|c|c|c|c|c|}
\hline \multicolumn{2}{|r|}{ Reasons } & 1 & 2 & 3 & 4 & 5 & 6 & 7 & 8 & 9 \\
\hline 1 & Used for buying other inputs & 1.000 & $0.813^{* *}$ & $0.737^{* *}$ & $-0.145^{* *}$ & $0.175^{* *}$ & $0.326^{* *}$ & $0.343^{* *}$ & $0.295^{* \star}$ & -0.006 \\
\hline 2 & Used for consumption purposes & 0.000 & 1.000 & $0.797^{* *}$ & $-0.113^{* *}$ & $0.169 * *$ & $0.286^{* *}$ & $0.366^{\star *}$ & $0.250^{* *}$ & -0.003 \\
\hline 3 & Used for meeting social expenses like marriage & 0.000 & 0.000 & 1.000 & $-0.122^{* *}$ & $0.196^{* *}$ & $0.305^{* *}$ & $0.359 * *$ & $0.244^{* *}$ & 0.030 \\
\hline 4 & Relaoned the amount & 0.000 & 0.000 & 0.000 & 1.000 & $-0.114 * *$ & $-0.112 * *$ & $-0.173^{* *}$ & $-0.157 * *$ & $0.090^{*}$ \\
\hline 5 & Used for repayment of other loan & 0.000 & 0.000 & 0.000 & 0.000 & 1.000 & 0.020 & 0.009 & $0.161^{* *}$ & $0.290^{* *}$ \\
\hline 6 & Cannot get the loan for actual purpose & 0.000 & 0.000 & 0.000 & 0.000 & 0.616 & 1.000 & $0.734 * *$ & $0.422 * *$ & -0.001 \\
\hline 7 & High rate of interest on loan for actual purpose & 0.000 & 0.000 & 0.000 & 0.000 & 0.826 & 0.000 & 1.000 & $0.511^{* *}$ & -0.057 \\
\hline 8 & Because it was insufficient for agricultural purposes & 0.000 & 0.000 & 0.000 & 0.000 & 0.000 & 0.000 & 0.000 & 1.000 & 0.019 \\
\hline 9 & Loan was received late & 0.876 & 0.940 & 0.447 & 0.022 & 0.000 & 0.974 & 0.151 & 0.635 & 1.000 \\
\hline
\end{tabular}

**Significant at $1 \%$ level

*Significant at $5 \%$ level

Note: Right Upper Triangle (Bold figures): Correlation ;

Left Lower Triangle (Unbold figures): Probability of Type I Error 